\title{
Intractable diarrhea-choanal atresia-eye anomalies syndrome
}

INSERM

\section{Source}

INSERM. (1999). Orphanet: an online rare disease and orphan drug data base. Intractable diarrhea-choanal atresia-eye anomalies syndrome. ORPHA:137622

Intractable diarrhea-choanal atresia-eye anomalies syndrome is characterised by the association of intractable diarrhoea of infancy with choanal atresia. Short stature, a prominent and broad nasal bridge, micrognathia, single palmar creases, chronic corneal inflammation, cytopenia, and abnormal hair texture were also reported. So far, the syndrome has been described in three children from the same family. The absence of intellectual deficit and immune deficiency allow this syndrome to be disting uished from other forms of intractable diarrhoea of infancy described previously. 